\title{
Estimation of Consumer Welfare Change from the Revi- sion of Age Criterion for BSE Testing: Hypothetical Re- vealed Preference Method Using Monitoring Survey Data
}

\author{
Fumihiro Yamane*
}

\begin{abstract}
The subject of this paper is to estimate consumers' welfare loss when the BSE testing age criterion for cattle is revised from all months to older than 21 months, by analyzing the change in meat demand due to this revision. However this analysis is different from ordinary revealed preference methods in that the demand data after this policy change are stated, while the data before this change are revealed as usual. This is because this paper focuses on a policy change which is not substantially executed yet. Using this demand data I estimated the generalized corner solution model of Phaneuf et al. (2000) for an incomplete demand system model. When I simulated each monitor's welfare loss based on the model estimation result, the expected compensating variation per household per month was 214 yen at the sample mean and 55 yen at the sample median.
\end{abstract}

Key words: BSE testing, age criterion revision, meat demand analysis, hypothetical revealed preference method, consumer welfare effect.

\section{Introduction}

The purpose of this research is to estimate the consumer welfare effect when BSE testing for butchery cattle starts to be carried out only for cattle aged 21 months or older through an analysis of the meat demand system. This information would be useful to examine a socially desirable direction of food safety administration in Japan from the perspective of cost-benefit analysis.

Some previous studies have analyzed the effects of past incidents or news related to BSE on domestic meat demand (Sawada [24], [25], Jin and Koo [12], Peterson and Chen [21], Oniki [20], Saghaian et al. [23]). However, these are ex post analyses of events that had already happened, so these cannot provide a method directly applicable to analysis of the effect of unprecedented events like the

\footnotetext{
*Kyoto University

This paper is based on Yamane [33], which was awarded 2009 Journal Article Prize of the Agricultural Economics Society of Japan.
}

abovementioned revision of BSE testing. Meanwhile Aizaki et al. [2] and McCluskey et al. [17] used stated preference methods to analyze the effects of some measures against BSE on price premiums of domestic beef. But neither analysis reflected the fact that consumers might adjust their demand for beef and its substitutes when measures were taken or abolished. In order to estimate a welfare measure that takes such an adjustment response into account, it is necessary to analyze the meat demand system as the first step.

Note that the revision of the age criterion for BSE testing has already been decided by law. The Food Safety Commission [28] stated that the BSE prion contamination rate in domestic beef was assessed to be "very small" and the amount of contamination to be "negligible" or "very small" even after the revision. Based on this assessment, the Japanese Government rescinded the legal liability for the testing of butchery cattle aged 20 months or younger in August, 2005. Nevertheless, all prefectures still voluntarily continue to test all aged butchery cattle (i. e. blanket test- 
ing); the cost of this voluntary testing was to be assisted by the government until July, 2008. This subsidy may be an interim measure for the fact that consumers desired blanket testing to be continued. ${ }^{1)}$ However, risk management agents, such as government, food safety specialist and meat producers, seem to consider that the desire of consumers is due to their lack of recognition of the degree of BSE risk or the risk reduction effect of blanket testing. Thus, there is no guarantee that blanket testing will be continued in the future.

In such a situation, despite accepting consumers' cognitive shortcomings, this study attempts an economic evaluation of continuing blanket testing based on their subjectivity.

The implications of this attempt are as follows. First, from a legal point of view consumers' desire should not be ignored since the Policy-Assessment System and the Food Safety Basic Act states policy decisions that reflect the needs and opinions of citizens. Second, if blanket testing is substantially abolished before the agreement of consumers is obtained, they might avoid purchasing domestic beef and cause an excessive welfare loss as a result. Therefore, we should evaluate this loss in advance. Attaching too much importance to the efficiency of risk management doesn't necessarily bring about economic efficiency. Third and finally, this welfare loss cannot be explained only by the cognitive lack of consumers. For instance, consumers are anxious in case the revision's complication of the testing process should cause mistakes and wrongdoing in testing operation, and this type of distrust may be another reason that they desire blanket testing (Yoshino et al. [35]). If so, we should accept a certain rationality of consumers' desire.

Note that the welfare effect estimated here is only a part of the effect which is revealed in the change of meat demand before and after the testing revision-the full welfare effect of the revision is not necessarily revealed in consumption activity. If we want to estimate the full effect, it would be appropriate to apply stated preference methods to estimate consumers' willingness to pay for blanket testing itself. Even so, revealed preference methods are expected to give us more re- liable results than stated preference methods in the sense that the former deals with actual activities of consumers.

However, this study does not practice a "pure" revealed preference method since the meat demand data used here is partially based on stated preference. To be concrete, while the demand data before the testing revision (ex ante demand) is revealed, the data after the revision (ex post demand) is stated, collected in a questionnaire in which I asked respondents to assume a hypothetical situation where BSE testing for butchery cattle aged 20 months or younger was completely abolished and to state their demand in this situation.

The problem that arises in this questionnaire is the reliability of the stated data. Although this study needs to analyze demand for domestic beef and its substitutes, it is too difficult for respondents to state their action in the hypothetical situation in such detail. So it is feared that their statements would suffer from excessive noise. To deal with this problem, before the questionnaire, I conducted a monitoring survey about purchase of meat with the same respondents for a month. After that, I informed each respondent about her own purchase record (purchase quantity and purchase price of each meat item in that survey period) as a reference point when she stated the ex post demand. This procedure is expected to be effective in making respondents state more realistic demand adjustment even if they don't accurately grasp their usual meat purchase status. Also, the monitoring record can be used as $e x$ ante demand data.

While an original reason to conduct this two-step survey is that there is no demand record under the hypothetical situation, we can also interpret this procedure affirmatively as it expands the applicability of revealed preference methods to a case where we want to evaluate a policy whose effect on demand for related commodities cannot be predicted easily in advance. As mentioned later, this procedure was devised to collect more desirable data for the purpose of this study based on careful examination of the characteristics of existing preference data which had been used in several previous studies.

Demand data collected by this procedure is 
in units of households, and few households purchased all item within a month. In such a situation, if we apply an incomplete demand system model ${ }^{2)}$ which assumes internal solutions, such as AIDS (almost ideal demand system) (Deaton and Muellbauer [5]), we can't obtain consistent estimators of the model parameters. Even if we exclude corner solution data from the sample, we can't solve the inconsistency and would lose the efficiency of the parameter estimates. In order to avoid these failures, it is appropriate to adopt a model which can handle corner solutions, and this study uses the generalized corner solution (GCS) model suggested by Phaneuf et al. [22]. The GCS model is classified as a Kuhn-Tucker approach. The Kuhn-Tucker approach begins its model specification by describing a utility maximization problem with nonnegativity constraints, so it has a theoretical advantage over the Amemiya-Tobin approach. ${ }^{3)}$

The rest of this paper proceeds as follows. In the next section, the characteristics of existing preference data are examined. Details of the two-step survey and collected data are described in section 3. As mentioned in section 4, inevitably this survey entails missing price data. How to deal with this problem is also explained in the same section. The theoretical derivation of the GCS model is provided in section 5 , and the estimation results of model parameters and the welfare effect are summarized in section 6 . The final section concludes this study.

\section{Selection of Preference Data}

In selecting analytical data, its representativeness and availability (or observability) are generally taken into account. In addition, given the purpose of this study, we have to consider the following three characteristics.

The first is applicability to hypothetical situations: blanket testing essentially continues even now and we don't have demand records after the revision, so it is necessary to supplement this shortage in some way. The second is usefulness to a demand system analysis: we need demand records not only for domestic beef but also for its substitutes. The third is reliability: since stated preference data, as previously mentioned, is not very reliable, we must devise a survey proce- dure so as to minimize the loss of reliability.

Bearing these characteristics in mind, this section examines the fitness of existing preference data for the purpose of this study.

1) Family Income and Expenditure Survey(FIES), Wholesale Market Survey (WMS) and Point-of-Sale System(POS)

These possess a certain reliability as revealed data and are useful in demand system analyses. However, some problems have been pointed out concerning their representativeness. ${ }^{4)}$

FIES is a monthly statistical survey concerning households' income, expenditure, saving and debt, and it contains a record of expenditure and purchase quantity for each food item. Concerning BSE, there are several case studies using FIES to analyze Japanese consumers' response to this risk. Sawada [25] focused on the relationship between safety information and food demand, and analyzed the effect on beef demand of newspaper reports about the first vCJD (variant Creutzfeldt Jakob Disease) patient having been confirmed in the UK in 1996. 5) Oniki [20] analyzed the change of consumers' MWTA (marginal willingness-to-accept), i. e. negative price premium per unit of beef, before and after 1996. Using a nonparametric test, Jin and Koo [12] indicated that the discovery of the first infected cattle in Japan in 2001 had caused a structural change in domestic meat demand.

WMS records the sales performance of perishables in the wholesale market. For meat demand system analysis, the Central Wholesale Market Survey and Statistics on Meat Marketing are useful. Peterson and Chen [21] used these data to analyze the effect of the outbreaks in 2001 on domestic meat demand.

POS records the sales performance of commodities in each retail store. POS has an advantage over FIES and WMS of recording consumer demand in more fractionalized commodity categories and in shorter periods. In fact, Sawada [24] attempted to improve the analysis of Sawada [25] by using weekly POS data: he was thereby able to analyze beef demand according to the country of origin (domestic, American and Australian beef) and to analyze the effect of newspaper reports in more detail than monthly data. Saghaian et al. [23] also used POS to analyze the effect 
of 2001's outbreak on the retail price of beef according to the country of origin.

As can be seen, even related to BSE alone, there are many case studies that use these demand records. However, it would be impossible to supplement the hypothetical demand data in a form comparable with these datathe Japanese meat market has never experienced the situation where BSE testing is conducted only for butchery cattle aged 21 months or older.

\section{2) Stated preference data}

Stated preference methods have also been used to evaluate the economic value of food safety. Through questionnaires or interviews, we can ask the respondents to state their preference under any hypothetical situation we are interested in.

However, it is not easy for the respondents to state their hypothetical demand in detail and it is feared that the statement would lose its reliability. Hence, previous studies seem to reduce the burden on respondents by simplifying the setting of questions. For instance, Aizaki et al. [2] conducted a choicebased conjoint analysis to estimate the price premium of beef due to BSE testing or additional production information labeling. In that attempt, Aizaki et al. [2] didn't question the respondents about how they adjusted their demand for beef and its substitutes when the testing and labeling was applied or not. The same is true of McClusky et al. [17], who conducted a dichotomous choicebased CVM (contingent evaluation method) to estimate the price premium of tested beef. Moreover, Sawada [26] reports some case studies using stated preference methods to evaluate food safety (not only about BSE) and none of these are exceptions, either. ${ }^{6)}$

MWTP obtained by such simplification has only limited implications in welfare analysis, and it is not a measure of my interest.

\section{3) Home scan data}

Home scan data is a commodity purchase record of household monitors. Since it captures a larger proportion of consumption expenditure than POS, it is useful to grasp the actual state of household demand more accurately. For this reason, the number of case studies using it is increasing. In the field of food safety, Mangen and Burrell [16] used it to analyze the effect of 1996's BSE incident on the meat demand system in the Netherlands, and Ujiie [29] also used it to analyze the effect on fluid milk demand in Japan of the food poisoning caused by Yukijirushi Dairy Corp. in 2000.

Furthermore, we can ask a research company to conduct an additional questionnaire to its monitors, and it is a powerful advantage for this study. This additional survey makes it possible to ask monitors about their decisions on purchase of meat in the hypothetical situation, and to use this stated data with usual purchase records to analyze the effect of the testing revision in advance.

In addition, in this survey, we can observe some consumer attributes which likely affect their food demand. Needless to say, different consumers have different meat demand, so the welfare effect caused by the testing revision varies between them, too. To consider such individual differences, we should deal with the heterogeneity of individual preferences. One way to do this is to specify consumers' utility as a function of their individual attributes, and Wales and Woodland [31], Heien and Wessells [10] and Cornick et al. [4] analyzed household demand for food in this way. While those studies used only monitor registration information, such as gender and age of household members, the additional survey allows us to use further information. Risk perception of consumers is of particular interest for the purpose of this study.

However, there are some problems with using home scan data. First, there is not enough data accumulation about perishables at present-home scan data has focused mainly on processed foods. Second, if any monitor didn't purchase the commodity of our interest in during the monitoring period, then we cannot observe its purchase price for her; it is not a negligible problem for this study because the price of fresh meat is not usually fixed. Third, as repeatedly mentioned, the reliability of the stated purchase data is not guaranteed. Fourth and finally, the source of home scan data is only households who agreed to be monitors, so it may not represent general household demand adequately.

Nevertheless, it is possible to deal with these problems to some degree. For the first 
problem, I conducted an independent monitoring survey about households' purchase of meat. For the second, I supplemented the loss of purchase prices by a method called "Regression", explained later. The approach to the third problem was already explained in section 1. Unfortunately, there is no effective method for dealing with the fourth problem. Therefore, I'll compare my data with FIES and show the difference between them.

\section{Survey and Data}

\section{1) Survey}

I contracted Do-House Corp. to conduct the two-step survey substitutively. Do-House Corp. is an internet research company targeting housewives aged in 30 s to 50 s who live in and around the Greater Tokyo Metropolitan area. Around 200 monitors were invited to co-operate in this survey. ${ }^{7)}$ Although there were 209 subjects at the start of the survey, the final sample size became 206 because of three dropouts. Table 1 shows a description of the monitor registration information.

The monitoring survey was conducted from February 19 to March 18 in 2007. In this survey, each monitor recorded her purchase quantity and expenditure for domestic beef (including Japanese beef), American beef (including Canadian beef), Australian beef (including New Zealand beef), pork, chicken and processed foods containing meat (such as processed meat (ham and sausage), retort pouch foods, instant foods and frozen foods). To be concrete, they kept receipts or notes of their food purchases and typed the information into a specific sheet every week.

Note that the purchase record regarding processed foods is such miscellaneous data that we cannot know from it the actual quantity of meat included. In addition, Sawada
[27] carried out nonparametric tests on consumer preference and indicated that weak separability of household demand for a commodity category composed of only fresh meat (beef, pork and chicken) was accepted. For these reasons, the purchase record of processed foods is excluded from the following analysis.

I collected the monitoring record on March 20 and calculated each monitor's purchase quantity and average purchase price of each item. Before the additional survey, I sent an E-mail about the contents of the questionnaire to the monitors. Also, in this mail, I reported to each monitor about her own purchase record (quantity and price of each item) and about the national average retail price of each item as a reference. ${ }^{8)}$ For the price of those items which were not purchased in the period, I reported "not purchased."

The questionnaire was conducted in a Web format from March 26 to 28. The flow of questions was as follows.

At the beginning, I asked about some consumer attributes: (a) taste for meat, (b) avoidance behavior based on risk of meat, (c) perception of safety of meat and (d) security obtained from blanket testing.

Here, "taste" is an attribute which indicates the strength of preference for the commodity of interest other than its safety. While there are some methods, such as LOGMAP suggested by Katahira [13], to grasp the strength of preference in a multifaceted form by analyzing consumers' emphasis on multiple attributes of the commodity (flavor, sense of extravagance, etc.), I attempted to grasp it in extremely simple form by asking the monitors to choose "the favorite meat item" from \{beef, pork, chicken or

Table 1. Age, number of household members and living area

\begin{tabular}{l|l|l}
\hline & \multicolumn{1}{|c|}{ Average } & \multicolumn{1}{c}{ Totaled results } \\
\hline Age & 41.5 years old & 30s $(93,45.1 \%), 40 \mathrm{~s}(88,42.7 \%), 50 \mathrm{~s}(25,12.1 \%)$ \\
\hline $\begin{array}{l}\text { Number of } \\
\text { household } \\
\text { members }\end{array}$ & $\begin{array}{l}3.6 \text { people per } \\
\text { household }\end{array}$ & $\begin{array}{l}\text { 2 people }(23,11.2 \%), 3 \text { people }(64,31.1 \%), 4 \text { people }(96,46.6 \%), 5 \text { people } \\
(19,9.2 \%), 6 \text { people }(3,1.5 \%), 7 \text { people }(1,0.5 \%)\end{array}$ \\
\hline \begin{tabular}{l} 
Living area \\
\hline
\end{tabular} & $\begin{array}{l}\text { Tokyo Metropolis (81, 39.3\%), Kanagawa Prefecture (65, 31.6\%), Saitama } \\
\text { Prefecture }(38,18.4 \%), \text { Chiba Prefecture }(22,10.7 \%)\end{array}$ \\
\hline
\end{tabular}


none $\}$ and to choose "the favorite beef item" from \{domestic beef, American beef, Australian beef or none\}.

The other questions are all about perceptions and attitudes towards meat safety. Regarding these attributes, Aizaki et al. [1] integrated conjoint analysis and the structural equation model to analyze the effect of consumers' knowledge of and attitude towards BSE or other food risks on their choice of beef alternatives, and indicated that "careful attitude towards risk" lowered their evaluation of commercial values of domestic and Australian beef and that "reliance for safety on domestic commodities" raised the evaluation of domestic beef. With reference to these results, I asked each monitor to choose "the items that she avoided purchasing because of risk anxiety" in place of "careful attitude towards safety" and to choose "the items that she thought to be completely safe" and "the items that she didn't think to be completely safe but ate without any anxiety" instead of "reliance for safety." In addition, after explaining about the contents and the risk reduction effect of blanket testing, I asked them to evaluate "the security due to this measure" on a scale of one to five; this information would be useful to identify "reliance for safety on domestic beef" further.

Next, I explained about the content and risk assessment of the testing revision and asked about food expenditure or its approxi- mate in the monitoring survey period.

Finally, I presented a scenario of the hypothetical situation (Figure 1) and asked about their purchases in the situation. In this question, I asked them to take the following three steps. First, they just typed their purchase price of each item recorded in the E-mail into the answer sheet. For "not purchased" cases, each monitor remembered the price of the corresponding item in her regular retail stores with reference to the recorded price of other items and its national average retail price and typed that price if she could remember. However, as this request seemed to be too difficult for them, they didn't answer more than half of such cases. Second, they just typed their purchase quantity of each item recorded in the E-mail. After confirming their own purchase status in this way, they finally typed their purchase quantity of each item in the hypothetical situation: to be concrete, I asked "How would you vary your purchase quantities from the status typed in step 2 if the age criterion of BSE testing was revised?"

\section{2) Data}

Sample average expenditure and purchase quantity of each item is summarized in Table 2. My sample exceeds FIES in both amount and quantity on average. But, given the fact that the average number of household members is about 3.6 in this sample, and it is larger than that of FIES (about 3.1), these

Figure 1. Scenario of hypothetical situation

Revision of safety measures for domestic beef (note: this is hypothetical)

Let's assume that it is impossible to continue BSE testing for butchery cattle aged 20 month or younger in the future, i. e. blanket testing will be abolished.

Please consider that this revision will change our situation as follows.

i ) Non-tested domestic beef (from cattle aged 20 month or younger) will be marketed to retail stores.

ii ) When we purchase a pack of domestic beef, we cannot distinguish between whether it is tested beef or not.

iii) Prices of domestic beef and other meat items won't change.

For reference, cattle aged 20 month or younger account for about $12.5 \%$ of all butchery cattle, i.e. one in eight (calculated based on 2004 data published by the Administrative Agency of the National Livestock Breeding Center). 
Table 2. Expenditure and purchase quantity of each meat item per household

\begin{tabular}{|c|c|c|c|c|}
\hline \multirow{2}{*}{ Item } & \multicolumn{2}{|c|}{$\begin{array}{l}\text { In monitoring period } \\
\text { (revealed data) }\end{array}$} & \multirow{2}{*}{$\begin{array}{l}\text { In hypothetical } \\
\text { situation (stated } \\
\text { data) }\end{array}$} & \multirow{2}{*}{$\begin{array}{l}\text { Change rate of } \\
\text { purchase quantity }\end{array}$} \\
\hline & Expenditure & Purchase quantity & & \\
\hline Domestic beef & 1,207 yen & $364 \mathrm{~g}$ & $323 \mathrm{~g}$ & $-11.3 \%$ \\
\hline American beef & 57 yen & $32 \mathrm{~g}$ & $73 \mathrm{~g}$ & $125.2 \%$ \\
\hline Australian beef & 646 yen & $417 \mathrm{~g}$ & $394 \mathrm{~g}$ & $-5.4 \%$ \\
\hline Pork & 2,796 yen & $2,251 \mathrm{~g}$ & $2,179 \mathrm{~g}$ & $-3.2 \%$ \\
\hline Chicken & 1,197 yen & $1,330 \mathrm{~g}$ & $1,419 \mathrm{~g}$ & $6.9 \%$ \\
\hline
\end{tabular}

Note: By a calculation of weighted average of expenditure and purchase quantity (per household and per month) in Tokyo's twenty-three wards, Yokohama City, Saitama City and Chiba City at the same ratio as Table 1 using the Annual Report on Family Income and Expenditure Survey 2006 (Results of Twoor-more-person Households), the average of beef is 1,724 yen and $561 \mathrm{~g}$, pork is 2,098 yen and 1,526 g and chicken is 942 yen and $950 \mathrm{~g}$.

differences wouldn't be so large in per capita values.

Regarding the change rate of purchase quantity before and after the testing revision, the mostly decreasing item is domestic beef. Although the purchase quantity of American beef increases remarkably, it seems to be because its original purchase quantity was too little.

Table 3 totals the combination of items that were purchased in the monitoring survey. Only $5 \%$ of monitors purchased all items. By item, 24 people (11.7\%) didn't purchase beef, one person (0.5\%) didn't buy pork and 15 people (7.3\%) didn't buy chicken. Considering only beef, 80 people $(38.8 \%)$ didn't purchase domestic beef, 187 people (90.8\%) didn't buy American beef and 73 people (35.4\%) didn't buy Australian beef.

The number "not purchased" is 356 of a total 1, 030 cases (5 items multiplied by 206 monitors), and 204 cases of those were "not answered" in step 1. Table 4 summarizes the sample average and standard deviation of prices other than these 204 cases. The reason why the prices of all items were less than the national average retail price may be that the monitors purchased at special sales.

Table 5 describes the definition and summary of consumer attributes. Originally ANXIETY is a rating datum, but it is converted into a dummy indicating whether the monitors felt anxiety even if blanket testing was taken. Although it would be ideal to convert it based on whether they didn't feel anxiety at all, I relaxed the converting criterion by one stage because only four (1.9\%) monitors answered "her family could eat domestic beef without any anxiety"; variables with much small variation like this would cause strong multicolinearity with the constant terms in the model estimation. Also, some monitor registration information, RATIOPRE, RATIOMALE and AGE, is added as consumer attributes with reference to Wales and Woodland [31], Heien and Wessells [10] and Cornick et al. [4].

According to Table 5, beef was popular with the monitors and domestic beef especially so. At the same time, while the safety of pork was widely recognized, the recognition that American beef was not safe was deeprooted.

\section{Handling Loss of Price Data}

In order to supplement the missing values of purchase price, I regress observed price on the other variables and fill in the missing parts with predicted prices obtained from this regression. This procedure is called "Regression," which is one of the single substitution methods in multivariate analysis with incomplete data (Iwasaki [11]). "Regression" has a certain average over other single substitution methods in the sense that we can do it without extreme loss of the variation which the corresponding variable originally has and, in addition, it is applicable even if we cannot easily identify the similarity among the observation units. ${ }^{9)}$ 
Table 3. Combination of purchased items

\begin{tabular}{|c|c|c|}
\hline \multicolumn{2}{|c|}{ Combination of purchase } & Count \\
\hline Only one item & $\begin{array}{l}\mathrm{P} \\
\mathrm{C}\end{array}$ & $\begin{array}{ll}1 & (0.5 \%) \\
1 & (0.5 \%)\end{array}$ \\
\hline Only two items & $\begin{array}{l}\text { J, P } \\
\mathrm{Au}, \mathrm{P} \\
\mathrm{P}, \mathrm{C}\end{array}$ & $\begin{array}{r}7(3.4 \%) \\
2(1.0 \%) \\
22(10.7 \%)\end{array}$ \\
\hline Only three items & $\begin{array}{l}\mathrm{J}, \mathrm{Au}, \mathrm{P} \\
\mathrm{J}, \mathrm{P}, \mathrm{C} \\
\mathrm{Am}, \mathrm{P}, \mathrm{C} \\
\mathrm{Au}, \mathrm{P}, \mathrm{C}\end{array}$ & $\begin{aligned} 5 & (2.4 \%) \\
39 & (18.9 \%) \\
1 & (0.5 \%) \\
47 & (22.8 \%)\end{aligned}$ \\
\hline Only four items & $\begin{array}{l}\mathrm{J}, \mathrm{Am}, \mathrm{P}, \mathrm{C} \\
\mathrm{J}, \mathrm{Au}, \mathrm{P}, \mathrm{C} \\
\mathrm{Am}, \mathrm{Au}, \mathrm{P}, \mathrm{C}\end{array}$ & $\begin{aligned} 2 & (1.0 \%) \\
63 & (30.6 \%) \\
6 & (2.9 \%)\end{aligned}$ \\
\hline All items & $\mathrm{J}, \mathrm{Am}, \mathrm{Au}, \mathrm{P}, \mathrm{C}$ & $10(4.9 \%)$ \\
\hline \multicolumn{2}{|c|}{ Total } & $206(100.0 \%)$ \\
\hline
\end{tabular}

Note: J (domestic beef), Am (American beef), Au (Australian beef), P (pork), C (chicken).

Table 4. Purchase price (yen per $100 \mathrm{~g}$ )

\begin{tabular}{crr}
\hline \multirow{2}{*}{ Item } & \multicolumn{2}{c}{ Price } \\
\cline { 2 - 3 } & Sample average & Standard deviation \\
\hline Domestic beef & 295.0 & 159.5 \\
American beef & 231.8 & 91.2 \\
Australian beef & 171.1 & 77.2 \\
Pork & 129.0 & 39.8 \\
Chicken & 100.7 & 40.1 \\
\hline
\end{tabular}

However, as the regression model is estimated with only the data whose price was observed, the estimate may suffer from sample-selection bias. Thus, I test this bias using Heckit, which is a statistical test procedure practiced through the two-stage estimation as follows.

At first, based on the concept of reservation price, the missing mechanism of price is formulated as

$$
\begin{aligned}
& x=0 \Longleftrightarrow p^{0} \geq p^{\mathrm{r}} \\
& x>0 \Longleftrightarrow p^{0}<p^{\mathrm{r}}
\end{aligned}
$$

$x$ is the purchase quantity of the good, $p^{\circ}$ is sale price and $p^{\mathrm{r}}$ is reservation price: reservation price means the maximum price which a consumer is subjectively willing to pay for the good. Equation(1) indicates that purchase price is observed if and only if it is less than the reservation price.

Based on this theory, the first stage of Heckit estimates the following probit model using all 1, 030 data.

$$
\operatorname{Prob}(d=1 \mid \boldsymbol{a})=\boldsymbol{\Phi}\left(-\boldsymbol{\delta}^{\prime} \boldsymbol{a}\right)
$$

$d$ is a dummy indicating whether the good was purchased or not. $\boldsymbol{a}$ is a vector of attributes which determine either purchase price or reservation price, or both; here $\boldsymbol{a}$ is specified by item-specific constants (JBEEF, AmBEEF, AuBEEF, PORK, CHICKEN), consumer attributes in Table 5, price level of meat at each monitor's regular retail store (PRICE LEVEL) and food expenditure (EXPEND). Since it is not possible to observe actual price level, I use average price of items which were purchased in the monitoring survey as a proxy. For example, if a monitor 
Table 5. Consumer attributes

\begin{tabular}{|c|c|c|}
\hline Variables & Definition & Totaled result \\
\hline TASTE 1 & $\begin{array}{l}\text { The favorite item of }\{\text { beef, pork, chicken }\}=1 \\
\text { Other items }=0\end{array}$ & $\begin{array}{ll}\text { Beef } & : 88(42.7 \%) \\
\text { Pork } & : 77(37.4 \%) \\
\text { Chicken } & : 31(15.1 \%)\end{array}$ \\
\hline TASTE 2 & $\begin{array}{l}\text { The favorite beef of }\{\text { domestic, American, Australian }\}=1 \\
\text { Other beef }=0\end{array}$ & $\begin{array}{l}\text { Domestic beef : } 186(90.3 \%) \\
\text { American beef : } 2(1.0 \%) \\
\text { Australian beef: } 9(4.4 \%)\end{array}$ \\
\hline AVOID & $\begin{array}{l}\text { Items that a monitor avoided purchasing because of risk } \\
\text { anxiety }=1 \\
\text { Other items }=0\end{array}$ & $\begin{array}{llr}\text { Domestic beef }: & 2(1.0 \%) \\
\text { American beef } & : & 126(61.2 \%) \\
\text { Australian beef : } & 26(12.6 \%) \\
\text { Pork } & : & 0(0.0 \%) \\
\text { Chicken } & : & 5(2.4 \%)\end{array}$ \\
\hline ZRISK & $\begin{array}{l}\text { Items that a monitor thought completely safe }=1 \\
\text { Other items }=0\end{array}$ & $\begin{array}{llr}\text { Domestic beef } & : & 76(36.9 \%) \\
\text { American beef } & : & 5(2.4 \%) \\
\text { Australian beef : } & 29(14.1 \%) \\
\text { Pork } & : & 105(51.0 \%) \\
\text { Chicken } & : & 46(22.3 \%)\end{array}$ \\
\hline LRISK & $\begin{array}{l}\text { Items that a monitor didn't think completely safe but ate } \\
\text { without anxiety }=1 \\
\text { Other items }=0\end{array}$ & $\begin{array}{ll}\text { Domestic beef }: & 99(48.1 \%) \\
\text { American beef }: & 51(24.8 \%) \\
\text { Australian beef : } & 113(54.9 \%) \\
\text { Pork } & : 102(49.5 \%) \\
\text { Chicken } & : 138(67.0 \%) \\
\end{array}$ \\
\hline ANXIETY & $\begin{array}{l}\text { "1. Those who couldn't eat domestic beef because of consid- } \\
\text { erable anxiety (even if blanket testing was taken)" }=1 \\
\text { "2. Those who couldn't eat because of slight anxiety" }=1 \\
\text { "3. Those who could eat with some security (due to blanket } \\
\text { testing)" =1 } \\
\text { “4. Those who could eat with considerable security" }=0 \\
\text { “5. Those who could eat with complete security"=0 }\end{array}$ & ANXIETY $=1: 166(80.6 \%)$ \\
\hline RATIOPRE & $\begin{array}{l}\text { Number of children aged } 6 \text { or younger } \div \text { number of household } \\
\text { members }\end{array}$ & Average $: 0.10$ \\
\hline RATIOMALE & Number of males $\div$ number of household members & Average : 0.49 \\
\hline AGE & Age of monitor & Average $: 41.5$ years old \\
\hline & Sample size & $20 \epsilon$ \\
\hline
\end{tabular}

purchased only domestic beef, pork and chicken, the average purchase price of these three items is regarded as a proxy of PRICE LEVEL for her. $\boldsymbol{\delta}$ is a parameter vector.

The estimation result of equation(2) is summarized in Table 6. Using this result, I calculate the inverse Mills ratio ( $\hat{\lambda})$ for 674 cases where the purchase prices were observed.
In the second stage, the regression model " $\log \left(p^{0}\right)$ on $\boldsymbol{a}_{1}, \hat{\lambda}$ " is estimated with only the 674 data. $\boldsymbol{a}_{1}$ is a vector of attributes which determine only purchase price, and, here, it is specified by the item-specific constants and PRICE LEVEL. We can test whether the price regression model we are interested in, i. e. " $\log \left(p^{0}\right)$ on $\boldsymbol{a}_{1}$," suffers from sampleselection bias based on the statistical signifi- 
Table 6. Estimation result of the first stage of heckit

\begin{tabular}{|c|c|c|}
\hline Variable & Coefficient & Standard error \\
\hline JBEEF & -6.56 & 1. $78^{* * *}$ \\
\hline AmBEEF & -6.66 & 1. $77^{* * *}$ \\
\hline AuBEEF & -5.36 & 1. $76^{* * *}$ \\
\hline PORK & -3.37 & 1. $77^{*}$ \\
\hline CHICKEN & -4.39 & $1.76^{* *}$ \\
\hline TASTE 1 & 0.20 & $0.12^{*}$ \\
\hline TASTE 2 (only for beef) & 0.64 & $0.28 * *$ \\
\hline AVOID & -0.99 & $0.23^{* * *}$ \\
\hline ZRISK & 0.88 & $0.17^{* * *}$ \\
\hline LRISK & 0.67 & $0.14^{* * *}$ \\
\hline ANXIETY (only for domestic beef) & 0.34 & 0.24 \\
\hline RATIOPRE & 0.54 & 0.42 \\
\hline RATIOMALE & -0.06 & 0.33 \\
\hline AGE & 0.03 & $0.01^{* * *}$ \\
\hline ln (PRICE LEVEL) & 0.30 & $0.15^{* *}$ \\
\hline $\ln (\mathrm{EXPEND})$ & 0.24 & 0.16 \\
\hline Log-likelihood & & -333.24 \\
\hline Sample size & & 1,030 \\
\hline
\end{tabular}

Table 7. Estimation result of the second stage of heckit and price regression model

\begin{tabular}{|c|c|c|c|c|}
\hline \multirow{2}{*}{ Variable } & \multicolumn{2}{|c|}{ Heckit } & \multicolumn{2}{|c|}{ OLS } \\
\hline & Coefficient & Standard error & Coefficient & Standard error \\
\hline JBEEF & 1. 34 & $0.16^{* * *}$ & 1. 31 & $0.19^{* * *}$ \\
\hline AmBEEF & 1.04 & $0.20 * * *$ & 0.98 & $0.19^{* * *}$ \\
\hline AuBEEF & 1.04 & $0.16^{* * *}$ & 1. 01 & $0.18 * * *$ \\
\hline PORK & 0.83 & $0.15^{* * *}$ & 0.82 & $0.18 * * *$ \\
\hline CHICKEN & 0.56 & $0.15^{* * *}$ & 0.54 & $0.18^{* * *}$ \\
\hline In (PRICE LEVEL) & 0.81 & $0.03^{* * *}$ & 0.81 & $0.04^{* * *}$ \\
\hline$\hat{\lambda}$ & -0.03 & 0.06 & & \\
\hline Adjusted R-squared & & 0.6831 & & 0.6834 \\
\hline Sample size & & 674 & & 674 \\
\hline
\end{tabular}

Note: 1$)^{* * *}: 1 \%$ significant level, ${ }^{* *}: 5 \%,^{*}: 10 \%$.

2) Standard errors in the result of OLS (right column) are heteroskedastic-robust.

cance of the parameter on $\hat{\lambda}$ : if the null hypothesis $H_{0}: \tau=0$ ( $\tau$ is a parameter on $\hat{\lambda}$ ) is not rejected by $t$ test, the existence of bias is not confirmed.

Table 7 shows estimation results of "log $\left(p^{0}\right)$ on $\boldsymbol{a}_{1}, \hat{\lambda}$ " and $" \log \left(p^{0}\right)$ on $\boldsymbol{a}_{1}$." The $p$ value of $\hat{\tau}$ is $61.99 \%$, so the null hypothesis is not rejected even at $10 \%$ significant level.
Moreover, the adjusted R-squared of the price regression model is not especially low (0.6834).

\section{The Generalized Corner Solution Model}

\section{1) Kuhn-Tucker approach}

In this subsection, I follow the Kuhn-Tucker approach, which is a theoretical founda- 
tion for the GCS model. To simplify the explanation, I'd like to here restrict the analytical object to a group of three items-beef (B), pork (P) and chicken (C).

The utility maximization problem is formulated as follows. $U(\cdot)$ is quasiconcave, continuously differentiable and increasing.

$$
\begin{array}{r}
\max _{x, z} U(\boldsymbol{x}, z ; \boldsymbol{q}, \boldsymbol{\Theta}, \boldsymbol{\varepsilon}) \\
\text { s.t.p' } \boldsymbol{x}+z \leq y, \boldsymbol{x} \geq \mathbf{0}, z \geq 0
\end{array}
$$

$\boldsymbol{x}=\left(x_{B}, x_{P}, x_{C}\right)$ is a purchase quantity vector, $z$ is a numeraire, $\boldsymbol{p}=\left(p_{B}, p_{P}, p_{C}\right)$ is a price vector and $y$ is food expenditure. $(\boldsymbol{q}, \boldsymbol{\Theta}$, $\boldsymbol{\varepsilon})$ is a vector of factors which determine the consumer's evaluation of the commercial value of each item: $\boldsymbol{q}=\left(\boldsymbol{q}_{B}, \boldsymbol{q}_{P}, \boldsymbol{q}_{C}\right)$ represents observed attributes, $\boldsymbol{\Theta}$ is a parameter vector and $\varepsilon=\left(\varepsilon_{B}, \varepsilon_{P}, \varepsilon_{C}\right)$ is an error vector.

By assuming an interior solution on $z$, we can obtain Kuhn-Tucker conditions as follows. Here, $U_{l}=\partial U / \partial x_{l}, \forall_{l}=\mathrm{B}, \mathrm{P}, \mathrm{C}$.

$$
\begin{aligned}
& U_{l}(\boldsymbol{x}, z ; \boldsymbol{q}, \boldsymbol{\Theta}, \boldsymbol{\varepsilon}) \leq p_{l} U_{z}(\boldsymbol{x}, z ; \boldsymbol{q}, \boldsymbol{\Theta}, \boldsymbol{\varepsilon}) \\
& x_{l} \geq 0 \\
& x_{l}\left[U_{l}-p_{l} U_{z}\right]=0 \quad \text { for all } l
\end{aligned}
$$

With the next three assumptions about the relationship between marginal utilities and errors

$$
\begin{array}{ll}
\partial U_{l} / \partial \varepsilon_{l}>0 & \text { for all } l \\
\partial U_{l} / \partial \varepsilon_{k}=0 & \text { for all } k \neq l \\
\partial U_{z} / \partial \varepsilon_{l}=0 & \text { for all } l
\end{array}
$$

Marginal utilities are rewritten as

$$
\begin{aligned}
& U_{l}(\boldsymbol{x}, z ; \boldsymbol{q}, \boldsymbol{\Theta}, \boldsymbol{\varepsilon})=U_{l}\left(\boldsymbol{x}, z ; \boldsymbol{q}, \boldsymbol{\Theta}, \boldsymbol{\varepsilon}_{l}\right) \text { for all } l \\
& U_{z}(\boldsymbol{x}, z ; \boldsymbol{q}, \boldsymbol{\Theta}, \boldsymbol{\varepsilon})=U_{z}(\boldsymbol{x}, z ; \boldsymbol{q}, \boldsymbol{\Theta})
\end{aligned}
$$

In addition, for any item, the solution of the next equation is defined as $g_{l} \equiv g_{l}(\boldsymbol{x}, \boldsymbol{p}, y ; \boldsymbol{q}$, $\boldsymbol{\Theta})$.

$$
U_{l}\left(\boldsymbol{x}, z ; \boldsymbol{q}, \boldsymbol{\Theta}, g_{l}\right)=p_{l} U_{z}(\boldsymbol{x}, z ; \boldsymbol{q}, \boldsymbol{\Theta})
$$

Then, Kuhn-Tucker conditions in equation (4) are rewritten as

$$
\begin{aligned}
& \varepsilon_{l} \leq g_{l}(\boldsymbol{x}, \boldsymbol{p}, y ; \boldsymbol{q}, \boldsymbol{\Theta}) \\
& x_{l} \geq 0 \\
& x_{l}\left[\varepsilon_{l}-g_{l}(\boldsymbol{x}, \boldsymbol{p}, y ; \boldsymbol{q}, \boldsymbol{\Theta})\right]=0 \text { for all } l
\end{aligned}
$$

The likelihood function necessary to estimate corner solution models is derived from equation (8). At first, for any monitor, let's denote the likelihood function by $h(\boldsymbol{x} \mid$ $\boldsymbol{\Theta})$ and the joint probability density function of $\varepsilon$ by $f(\varepsilon)$. Then, for instance, the likelihood for monitors those who purchased all item ( $\boldsymbol{x} \gg \mathbf{0}$, i. e. perfect interior solution) is represented by

$$
h(\boldsymbol{x} \mid \boldsymbol{\Theta})=f(\boldsymbol{g}) \text { abs }\left|J_{\text {all }}\right|
$$

$\left|J_{\text {all }}\right|$ is a Jacobian of a vector-function map- ping $\varepsilon$ to $x$, which is derived from equation (8). On the other hand, the likelihood for monitors those who didn't purchase any item $(\boldsymbol{x}=\mathbf{0}$, i. e. perfect corner solution) is

$$
h(\mathbf{0} \mid \boldsymbol{\Theta})=\int_{-\infty}^{g_{B}} \int_{-\infty}^{g_{P}} \int_{-\infty}^{g_{C}} f(\boldsymbol{\varepsilon}) d \varepsilon_{B} d \varepsilon_{P} d \varepsilon_{C}
$$

The likelihood for monitors with the other purchase status, e.g. those who purchased only pork and chicken $\left(x_{B}=0, x_{P}>0, x_{C}>0\right)$ is

$$
h\left(0, x_{P}, x_{C} \mid \boldsymbol{\Theta}\right)=\int_{-\infty}^{g_{B}} f\left(\varepsilon_{B}, g_{P}, g_{C}\right) a b s\left|J_{(P, C)}\right| d \varepsilon_{B}
$$

$\left|J_{(P, C)}\right|$ is a Jacobian of a vector-function mapping $\varepsilon$ to $\left(\varepsilon_{B}, x_{P}, x_{C}\right)$.

\section{2) Estimation model}

From here, I explain the estimation model; the analytical object returns to a group of five items-domestic beef $(\mathrm{J})$, American beef $(\mathrm{Am})$, Australian beef $(\mathrm{Au})$, pork $(\mathrm{P})$ and chicken $(\mathrm{C})$.

With reference to Phaneuf et al. [22], the utility function is specified as follows.

$$
\begin{aligned}
& U(\boldsymbol{x}, z ; \boldsymbol{q}, \boldsymbol{\beta}, \boldsymbol{\varepsilon}) \\
& =\sum_{l=\mathrm{J}, \mathrm{Am}, \mathrm{Au}, \mathrm{P}, \mathrm{C}} \Psi_{l}\left(\boldsymbol{q}_{l}, \varepsilon_{l}\right) \log \left(x_{l}+1\right)+\log (z) \\
& \quad \text { where } \Psi_{l}\left(\boldsymbol{q}_{l}, \varepsilon_{l}\right)=\exp \left(\boldsymbol{\beta}^{\prime} \boldsymbol{q}_{l}+\varepsilon_{l}\right) \quad \text { for all } l
\end{aligned}
$$

$\Psi_{l}$ represents the consumer's evaluation of the commercial value of item $l$, and it is specified as a linear function of item-specific constants and consumer attributes in Table 5. Regarding $\Psi_{\mathrm{J}}$, a dummy indicating whether the testing revision is taken or not (POLICY) is also added as its determinant; the change of commercial value evaluation for domestic beef is described in this way. $g_{l}$ for this utility function is

$$
g_{l}=\log \left(\frac{p_{l}\left(x_{l}+1\right)}{y-\boldsymbol{p}^{\prime} \boldsymbol{x}}\right)-\boldsymbol{\beta}_{l}^{\prime} \boldsymbol{q}_{l} \quad \text { for all } l
$$

Next, I assume $\varepsilon$ to follow generalized extreme value (GEV) distribution with a nest consisting of beef items, i. e. a beef nest. As a result, we can describe the likelihood function in closed-form and can take the correlation among errors within the nest into account. ${ }^{10)}$ In this case, the cumulative density function of $\varepsilon$ is

$$
\begin{aligned}
F(\boldsymbol{\varepsilon})= & \exp \left[-\left(\sum_{l=\mathrm{J}, \mathrm{Am}, \mathrm{Au}} \exp \left(\frac{-\varepsilon_{l}}{\mu \rho}\right)\right)^{\rho}\right. \\
& \left.-\exp \left(\frac{-\varepsilon_{P}}{\mu}\right)-\exp \left(\frac{-\varepsilon_{C}}{\mu}\right)\right]
\end{aligned}
$$

$\rho$ represents the strength of independency among errors within the nest. $\mu$ is a scale pa- 
rameter: in order to deal with heteroskedasticity among the monitors, I specify it as $\mu=$ $\exp \left(\boldsymbol{\gamma}^{\prime} \boldsymbol{q}\right)$ with reference to Wooldridge [32, p. 463] (here, POLICY is not included in $\boldsymbol{q}$ ).

Under these assumptions, the log-likelihood function for each monitor is derived as follows.

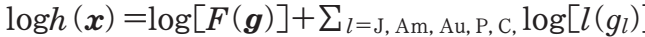

$$
\begin{aligned}
& +\left[\sum_{l=\mathrm{J}, \mathrm{Am}, \mathrm{Au}} d_{l}\right](\boldsymbol{\rho}-1) \log \left[B\left(\boldsymbol{g}_{B}\right)\right] \\
& +\frac{1}{2}\left[\sum_{l=\mathrm{J}, \mathrm{Am}, \mathrm{Au}}\right. \\
& \left.\sum_{k \neq 1} d_{l} d_{k}\left(1-d_{j \neq l, k}\right)\right] \log \left[B^{\prime}\left(\boldsymbol{g}_{B}\right)\right] \\
& +\left[\Pi_{l=\mathrm{J}, \mathrm{Am}, \mathrm{Au}} d_{l}\right] \log \left[B^{\prime \prime}\left(\boldsymbol{g}_{B}\right)\right] \\
& -\left[\sum_{l=\mathrm{J}, \mathrm{Am}, \mathrm{Au}, \mathrm{P}, \mathrm{C}} d_{l}\right] \log (\mu) \\
& \log \left[\text { abs }\left|J_{\bar{\sigma}}\right|\right] \\
& l\left(g_{l}\right)=\left\{\begin{array}{l}
\exp \left(\frac{-g_{l}}{\mu \rho}\right) \text { for } l=\mathrm{J}, \mathrm{Am}, \mathrm{Au} \\
\exp \left(\frac{-g_{l}}{\mu}\right) \text { for } l=\mathrm{P}, \mathrm{C}
\end{array}\right. \\
& B\left(\boldsymbol{g}_{B}\right)=\sum_{l=\mathrm{J}, \mathrm{Am}, \mathrm{Au}} l\left(g_{l}\right) \\
& B^{\prime}\left(\boldsymbol{g}_{B}\right)=1-\frac{\rho-1}{\rho} B\left(\boldsymbol{g}_{B}\right)^{-\rho} \\
& B^{\prime \prime}\left(\boldsymbol{g}_{B}\right)=1-\frac{3 \rho-3}{\rho} B\left(\boldsymbol{g}_{B}\right)^{-\rho} \\
& +\frac{\rho^{2}-3 \rho+2}{\rho^{2}} B\left(\boldsymbol{g}_{B}\right)^{-2 \rho}
\end{aligned}
$$

$d_{l}$ is a dummy indicating whether the observation of $x_{l}$ is an interior solution or not. Incidentally, Jacobian doesn't contribute the likelihood maximization in equation(15) in any way, so we can exclude it at estimation.

\section{3) Compensating Variation (CV)}

In order to define $\mathrm{CV}$ in corner solution models, Phaneuf et al. [22] assumed a twostage optimization problem which appeared in Hanemann [9]'s discrete/continuous models. To begin with, it is assumed that consumers seek their optimal behaviors for any corner solution pattern. For example, in the case of three items (beef, pork and chicken), there are eight patterns of corner solution: $\boldsymbol{\Omega}$ $=\{\phi, \mathrm{B}, \mathrm{P}, \mathrm{C},(\mathrm{B}, \mathrm{P}),(\mathrm{B}, \mathrm{C}),(\mathrm{P}, \mathrm{C})$, all $\}$, and, in a pattern of $(\mathrm{P}, \mathrm{C})$, consumers maximize their utilities subject to a restriction that they don't purchase beef. That is, for any pattern $(\varpi \in \Omega)$, the conditional indirect utility function is defined as

$$
\begin{aligned}
V_{\bar{\sigma}}\left(\boldsymbol{p}_{\bar{\sigma}}, y ; \boldsymbol{q}_{\boldsymbol{\sigma}}, \boldsymbol{\Theta}, \boldsymbol{\varepsilon}_{\bar{\sigma}}\right) \equiv & \max _{x, z} U(\boldsymbol{x}, z ; \boldsymbol{q}, \boldsymbol{\Theta}, \boldsymbol{\varepsilon}) \\
& \text { s.t. } \sum_{l \in \varpi} p_{l} x_{l}+z \leq y \\
& x_{l} \geq 0 \text { for } l \in \boldsymbol{\sigma} \\
& x_{k}=0 \text { for } k \notin \varpi \\
& z \geq 0
\end{aligned}
$$

In addition, it is assumed that consumers choose a pattern which maximizes this conditional indirect utility. Under these assumptions, CV in corner solution models is defined as

$$
\begin{aligned}
& \max _{\varpi \in \Omega}\left[V_{\varpi}\left(\boldsymbol{p}_{\pi}, y ; \boldsymbol{q}_{\pi}^{0}, \boldsymbol{\Theta}, \boldsymbol{\varepsilon}_{\varpi}\right)\right] \\
& \equiv \max _{\pi \in \Omega}\left[V_{\varpi}\left(\boldsymbol{p}_{\pi}, y+C V ; \boldsymbol{q}_{\pi}^{1}, \boldsymbol{\Theta}, \boldsymbol{\varepsilon}_{\pi}\right)\right](17)
\end{aligned}
$$

In this study, I calculate expected $\mathrm{CV}$ for each monitor based on this definition and obtain sample mean and median of these expectations. Since the expected CV derived from equation(12) is not closed-form, I simulate its approximate. Also, since I assumed GEV distribution for $\varepsilon$, I practice McFadden [18]'s Markov chain Monte-Carlo simulation with reference to Phaneuf et al. [22]. The procedure for this simulation is as follows.

I) For any monitor $n$, generate $10,000 \mathrm{vec}$ tors of random number $\varepsilon^{n}=\left(\varepsilon_{\mathrm{J}}^{n}, \varepsilon_{\mathrm{Am}}^{n}, \varepsilon_{\mathrm{Au}}^{n}\right.$, $\left.\varepsilon_{\mathrm{P}}^{n}, \varepsilon_{\mathrm{C}}^{n}\right)$ which asymptotically possess the property of GEV distribution through Markov chain process. Denote the $r$ th vector by $\varepsilon^{n r}$.

II) Using estimation result of GCS model and $\varepsilon^{n r}$, calculate $C V^{n r}$ for all $r$. Arrange $\left(C V^{n 1}, \ldots, C V^{n 10000}\right)$ in order of amount and denote it again by $\left(C V^{*} n 1\right.$, $\left.\ldots, C V^{*} n 10000\right)$. Then, exclude 5,000 values which are less than the first quartile point or more than the third quartile point, and calculate the average of the remaining values. Regard it as an approximate of expected CV for monitor $n .^{11)}$

$$
\mathrm{E}_{\bar{\sigma}}\left[C V_{n}\left(\boldsymbol{p}_{n}, y_{n} ; \boldsymbol{q}_{n}^{0}, \boldsymbol{q}_{n}^{1}, \hat{\boldsymbol{\beta}}, \boldsymbol{\varepsilon}\right)\right] \approx \frac{1}{5000_{s}=2501} \sum^{7500} C V^{*} n s
$$

III) Repeat steps I and II for every monitor.

\section{Estimation Results}

\section{1) Estimation results of GCS model}

Table 8 shows the estimation result of the GCS model: the estimation result about heteroskedasticity $\left(\boldsymbol{\mu}=\exp \left(\boldsymbol{\gamma}^{\prime} \boldsymbol{q}\right)\right)$ is shown in Table 9. A positive parameter indicates that the attribute raises commercial value evaluation for the item, and negative parameter indicates vice versa. Although some of the estimates are not significant even at $10 \%$, these insignificances seem to be not a little affected by the limited sample size. Also, this study cannot deal with endogeneity of price 
and expenditure in demand analysis. ${ }^{12)}$ For example, this problem is severely treated in empirical development economics (Fuwa [8]). In contrast, in a field of food safety, many studies couldn't have dealt with it. So, it should be emphasized that endogeneity is a significant problem which we will have to treat henceforth in this field.

Estimates of the parameters on TASTE1 and TASTE2 are all positive. This would be an interpretable result because it indicates that a monitor highly evaluated the commercial value of the favorite item.

Results concerning perception and attitude towards safety are almost consistent with Aizaki et al. [1]. Parameter estimates of AVOID are all negative, indicating that a monitor lowered her evaluation for items which she avoided purchasing. Estimates of ZRISK and LRISK are almost all positive, indicating that she highly evaluated the items which she thought to be completely safe or so safe that she was not worried about them. Although the parameter on LRISK of pork is negative, it is not significant. The parameter on ANXIETY is negative, indicating that those who were anxious about risk even with blanket testing lowered the evaluation for domestic beef.

The parameter on POLICY is significantly negative, so it indicates that the evaluation for domestic beef was lowered after the testing revision.

As other significant results, (a) the higher the ratio of children aged 6 or younger, the higher the evaluation of domestic and Australian beef and the lower for American beef, (b) the older the monitor, the higher the evaluation of domestic and Australian beef.

The estimate of $\rho$ is significantly different from one, but its value doesn't indicate strong correlation within the beef nest.

Next, I simulated the expectation of price and expenditure elasticity for each monitor. Elasticities derived from equation (12) are as follows. In the case where the predicted demand for item $l$ becomes a corner solution $\left(x_{l}^{*}\right)$ in the simulation process, it is not possible to calculate its elasticities and I set them to zero.

Table 8. Estimation result of generalized corner solution model

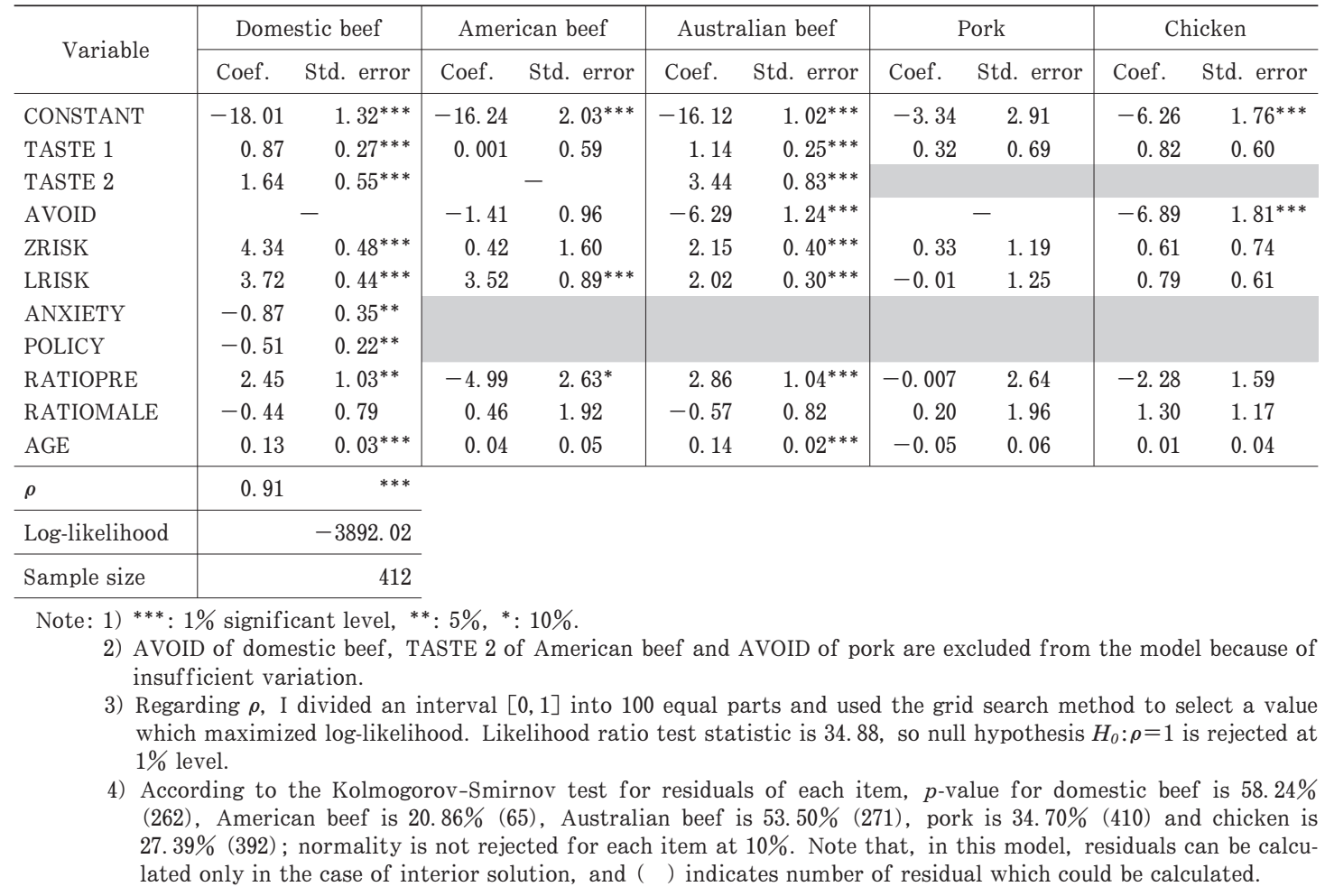


Table 9. Estimation result of heteroskedasticity

\begin{tabular}{l|rc}
\hline Variable & Coefficient & Std. error \\
\hline TASTE1 (B) & 0.08 & 0.11 \\
TASTE1 (P) & 0.04 & 0.11 \\
TASTE1 (C) & -0.19 & 0.12 \\
TASTE2 (J) & 0.54 & $0.13^{* * *}$ \\
TASTE2 (Au) & 0.74 & $0.16^{* * *}$ \\
AVOID (Am) & 0.16 & $0.08^{*}$ \\
AVOID (Au) & -0.10 & 0.09 \\
AVOID (C) & 0.56 & $0.17^{* * *}$ \\
ZRISK (J) & 0.31 & $0.06^{* * *}$ \\
ZRISK (Am) & -0.08 & 0.20 \\
ZRISK (Au) & 0.17 & $0.10^{*}$ \\
ZRISK (P) & 0.12 & 0.08 \\
ZRISK (C) & -0.24 & $0.11^{* *}$ \\
LRISK (J) & 0.18 & $0.06^{* * *}$ \\
LRISK (Am) & 0.31 & $0.08^{* * *}$ \\
LRISK (Au) & -0.002 & 0.07 \\
LRISK (P) & -0.03 & 0.08 \\
LRISK (C) & -0.13 & 0.10 \\
ANXIETY & 0.09 & 0.07 \\
RATIOPRE & 0.28 & 0.25 \\
RATIOMALE & 0.18 & 0.17 \\
AGE & -0.003 & 0.004 \\
\hline
\end{tabular}

Note: 1) ${ }^{* * *}: 1 \%$ significant level, ${ }^{* *}: 5 \%,{ }^{*}: 10 \%$.

2) ( ) represents initials of items-TASTE 1 (B) is a dummy indicating whether a monitor liked beef best of \{beef, pork, chicken\}, AVOID (Am) is a dummy indicating whether she avoided purchasing American beef, etc. For the same reason as in Table 8, AVOID $(\mathrm{J})$, TATSE2 (Am) and AVOID (P) are excluded from the model.

$$
\begin{aligned}
& \frac{p_{l}}{x_{l}^{*}} \frac{\partial x_{l}^{*}}{\partial p_{l}}=-\frac{1}{x_{l}^{*}} \frac{\Psi_{l}}{1+\sum_{k \in \Phi^{*}} \Psi_{k}} \frac{y+\sum_{k \in \Phi^{*}, k \neq l} p_{k}}{p_{l}} \\
& \frac{p_{m}}{x_{l}^{*}} \frac{\partial x_{l}^{*}}{\partial p_{m}}= \begin{cases}\frac{1}{x_{l}^{*}} \frac{\Psi_{l}}{1+\sum_{k \in \sigma^{*}} \Psi_{k}} \frac{p_{m}}{p_{l}} & \text { if } m \in \sigma^{*} \\
0 & \text { otherwise }\end{cases} \\
& \text { for } m \neq l \\
& \frac{y}{x_{l}^{*}} \frac{\partial x_{l}^{*}}{\partial y}=\frac{1}{x_{l}^{*}} \frac{\Psi_{l}}{1+\sum_{k \in \sigma^{*}} \Psi_{k}} \frac{y}{p_{l}}
\end{aligned}
$$

where $\varpi^{*} \equiv \operatorname{argmax}_{\bar{\sigma} \in \Omega}\left[V_{\bar{\sigma}}\left(\boldsymbol{p}_{\bar{\sigma}}, y ; \boldsymbol{q}_{\bar{\sigma}}, \boldsymbol{\Theta}, \boldsymbol{\varepsilon}_{\bar{\sigma}}\right)\right]$

Sample means of expected elasticities before and after the testing revision are summarized in Tables 10 and 11, respectively.

Of expenditure elasticities before the revision, that of domestic beef is the largest and American beef is the smallest. Yet we should be careful when interpreting this result. Remember that elasticity was set to zero in the case of a corner solution, and it means that the expected elasticity of the item whose demand is frequently predicted to be zero tends to be small. Thus, the fact that elasticity of domestic beef is the largest, even though it has more frequency of corner solutions than pork or chicken, indicates that it was widely recognized as a luxury good. Meanwhile, the result for American beef seems to be largely influenced by the fact that it has the most frequency of corner solutions.

While the expenditure elasticity of domestic beef declines after the revision, there is no remarkable change for the other items.

On the other hand, cross price elasticities are all positive but almost zero. As reasons for this, there are several possibilities. First, $\Psi_{l}$ calculated in the simulation of ten takes an extremely small value. ${ }^{13)}$ Second, $y$ doesn't remain in the denominator of cross price elasticity (see equation(20)) whereas it remains in the case of own price and expenditure elasticity (see equation(19) and (21)). Third, elasticities were set to zero in corner solution cases.

Also, own price elasticities are almost equal to negatives of expenditure ones as is obvious from equation (19) and (21).

\section{2) Estimation results of $\mathrm{CV}$}

As a result of the simulation for expected $\mathrm{CV}$ of each monitor, the sample mean is 214 yen/household $\cdot$ month and the median is 55 yen/household $\cdot$ month. However, note that these are the welfare effects in a month just after the testing revision and these may calm down in the long-run.

As a reference, if these estimates are multiplied by the national average number of household members (about 2.6 people; data source is National Census of 2005)/the sample average (about 3.6 people) and by the total number of households (about 49.57 million households; data source as above), the sample average becomes about 7.6 billion yen/ month and the median becomes about 2.0 billion yen/month. Even though we shouldn't regard it as the whole consumer welfare loss in Japan because the level of price and expenditure is not the same all over the nation, it seems to sufficiently exceed the cost of BSE testing for butchery cattle aged 20 
Table 10. Simulation result of elasticities before the testing revision

\begin{tabular}{l|ccccc}
\hline Item & Domestic beef & American beef & Australian beef & Pork & Chicken \\
\hline \multirow{2}{*}{ Domestic beef price } & -1.7979 & $2.1802 \times 10^{-5}$ & $5.1876 \times 10^{-5}$ & $3.8352 \times 10^{-5}$ & $3.8853 \times 10^{-5}$ \\
& $(0.8173)$ & $\left(2.6425 \times 10^{-5}\right)$ & $\left(3.4096 \times 10^{-5}\right)$ & $\left(6.9538 \times 10^{-5}\right)$ & $\left(0.6685 \times 10^{-5}\right)$ \\
American beef price & $1.7413 \times 10^{-5}$ & -0.5895 & $1.0623 \times 10^{-5}$ & $0.5798 \times 10^{-5}$ & $0.7043 \times 10^{-5}$ \\
& $\left(1.7634 \times 10^{-5}\right)$ & $(0.5627)$ & $\left(1.9392 \times 10^{-5}\right)$ & $\left(1.8494 \times 10^{-5}\right)$ & $\left(0.3748 \times 10^{-5}\right)$ \\
Australian beef price & $3.0404 \times 10^{-5}$ & $1.5302 \times 10^{-5}$ & -1.4477 & $2.4755 \times 10^{-5}$ & $2.3515 \times 10^{-5}$ \\
& $\left(0.2917 \times 10^{-5}\right)$ & $\left(1.9346 \times 10^{-5}\right)$ & $(0.7131)$ & $\left(4.7492 \times 10^{-5}\right)$ & $\left(0.3032 \times 10^{-5}\right)$ \\
Pork price & $4.5966 \times 10^{-5}$ & $1.5304 \times 10^{-5}$ & $3.9722 \times 10^{-5}$ & -1.0889 & $2.9547 \times 10^{-5}$ \\
& $\left(1.6460 \times 10^{-5}\right)$ & $\left(1.3007 \times 10^{-5}\right)$ & $\left(2.3998 \times 10^{-5}\right)$ & $(0.2930)$ & $\left(0.4033 \times 10^{-5}\right)$ \\
Chicken price & $3.6363 \times 10^{-5}$ & $1.1007 \times 10^{-5}$ & $3.0143 \times 10^{-5}$ & $2.2176 \times 10^{-5}$ & -1.1055 \\
& $\left(1.5666 \times 10^{-5}\right)$ & $\left(0.9581 \times 10^{-5}\right)$ & $\left(1.9932 \times 10^{-5}\right)$ & $\left(3.4241 \times 10^{-5}\right)$ & $(0.1828)$ \\
Food expenditure & 1.7977 & 0.5894 & 1.4475 & 1.0888 & 1.1054 \\
& $(0.8168)$ & $(0.5626)$ & $(0.7130)$ & $(0.2930)$ & $(0.1827)$ \\
\hline
\end{tabular}

Note: ( ) indicates standard deviation.

Table 11. Simulation result of elasticities after the testing revision

\begin{tabular}{l|ccccc}
\hline Item & Domestic beef & American beef & Australian beef & Pork & Chicken \\
\hline \multirow{2}{*}{ Domestic beef Price } & -1.3517 & $1.3264 \times 10^{-5}$ & $4.9084 \times 10^{-5}$ & $3.4674 \times 10^{-5}$ & $3.3716 \times 10^{-5}$ \\
& $(0.4679)$ & $\left(4.9598 \times 10^{-5}\right)$ & $\left(4.1222 \times 10^{-5}\right)$ & $\left(2.6412 \times 10^{-5}\right)$ & $\left(0.4790 \times 10^{-5}\right)$ \\
American beef price & $0.9252 \times 10^{-5}$ & -0.5869 & $1.0590 \times 10^{-5}$ & $0.5604 \times 10^{-5}$ & $0.6360 \times 10^{-5}$ \\
& $\left(1.1863 \times 10^{-5}\right)$ & $(0.5940)$ & $\left(1.7513 \times 10^{-5}\right)$ & $\left(0.7916 \times 10^{-5}\right)$ & $\left(0.3476 \times 10^{-5}\right)$ \\
Australian beef price & $2.8633 \times 10^{-5}$ & $1.5367 \times 10^{-5}$ & -1.4744 & $2.4420 \times 10^{-5}$ & $2.3219 \times 10^{-5}$ \\
& $\left(0.8147 \times 10^{-5}\right)$ & $\left(2.3609 \times 10^{-5}\right)$ & $(0.7578)$ & $\left(2.1308 \times 10^{-5}\right)$ & $\left(0.3849 \times 10^{-5}\right)$ \\
Pork price & $3.6924 \times 10^{-5}$ & $1.5224 \times 10^{-5}$ & $4.0547 \times 10^{-5}$ & -1.0748 & $2.9507 \times 10^{-5}$ \\
& $\left(1.4503 \times 10^{-5}\right)$ & $\left(1.5169 \times 10^{-5}\right)$ & $\left(2.4550 \times 10^{-5}\right)$ & $(0.2534)$ & $\left(0.4512 \times 10^{-5}\right)$ \\
Chicken price & $2.9105 \times 10^{-5}$ & $1.1174 \times 10^{-5}$ & $3.0796 \times 10^{-5}$ & $2.1875 \times 10^{-5}$ & -1.0975 \\
& $\left(1.5854 \times 10^{-5}\right)$ & $\left(1.1942 \times 10^{-5}\right)$ & $\left(1.9778 \times 10^{-5}\right)$ & $\left(1.4987 \times 10^{-5}\right)$ & $(0.1929)$ \\
Food expenditure & 1.3515 & 0.5868 & 1.4742 & 1.0747 & 1.0974 \\
& $(0.4677)$ & $(0.5939)$ & $(0.7577)$ & $(0.2534)$ & $(0.1929)$ \\
\hline
\end{tabular}

Note: ( ) indicates standard deviation.

month or younger (about 0.3-0. 4 billion yen/ year; source is the article of Mainichi Newspaper in May 25, 2007).

In addition, I'd like to discuss the magnitude of this effect in comparison with the evaluation results of Oniki [20] and McCluskey et al. [17].

Oniki [20] analyzed meat demand from January 1990 to March 1998 and estimated that the consumer surplus lowered by 5,094 yen/household in 1996 when the BSE crisis and $\mathrm{O} 157$ food poisoning incident happened. In contrast, if I multiply the above estimates simply by twelve, the sample average becomes 2, 579 yen/household and the median becomes 660 yen/household: the annual effect of the testing revision is expected to be smaller than these because of the calming effect mentioned above. Nevertheless, considering the fact that the abolition of BSE testing is partial-only for younger cattle-it would still be a large effect.

On the other hand, McCluskey et al. [17] carried out CVM in December, 2001 (just after the BSE crisis in 2001) and estimated that the average respondent's MWTP for domestic beef rose by $50 \%$ thanks to BSE testing. Compared with this, if I simulate the expectation of the following MWTA based on the result in Table 8 , the MWTA of the average household in my sample is $25.68 \%$ of price: $e_{J J}$ is own price elasticity of domestic beef 
and the superscript figure indicates whether the testing is revised or not. ${ }^{14)}$

$$
M W T A_{J}=p_{J} \frac{x_{J}^{1^{*}}-x_{J}^{0^{*}}}{x_{J}^{0^{*}}} \frac{1}{e_{J J}^{0}}
$$

This result indicates that the price premium of domestic beef would decline by $25.68 \%$ because of the revision. Although five years and six months have passed since the 2001 crisis, and although the revision is a partial one, the price premium caused by blanket testing still seems to be large.

Why do Japanese consumers evaluate blanket testing so highly?

As mentioned in section 1, there are two possibilities for this evaluation. One is consumers' cognitive lack on BSE risk and the risk reduction effect of blanket testing, and the other is their distrust of the total permeation of BSE testing. After the 2001 crisis, the political decision against BSE was overturned many times and several mistakes and wrongdoings in risk management were found in succession. A series of these events probably caused consumers' distrust of scientific risk management and its thoroughness. In addition, there is asymmetric information in the sense that consumers cannot check the thoroughness unless some accident is found. In such a situation, even if consumers desire scientifically excessive measures against risk, we shouldn't conclude that their desire is irrational.

If such reasoning substantially causes a large welfare loss, there is a necessity to tackle the cognitive lack and the distrust even if BSE testing for cattle aged 20 months or younger is abolished. Without such measures, the revision will impose an additional welfare loss on consumers.

Concerning the cognitive lack, it is necessary to improve consumers' risk perception. For instance, one improvement would be that consumers understand that blanket testing never guarantees zero risk. If the monitors who thought that the risk of domestic beef was zero $(Z R I S K=1)$ improve their perception to the risk being not zero but sufficiently small (LRISK $=1)$, then the sample average of the expected $\mathrm{CV}$ becomes $147 \mathrm{yen} /$ month and the median becomes 31 yen/month. Of course, it is also important to have consumers understand that BSE risk is extremely small even if the testing is revised.
For the distrust, it is necessary to prepare the ground whereby the thoroughness of BSE testing is guaranteed even after the revision. However, I cannot analyze this effect on $\mathrm{CV}$ only with the survey data, so leave it as a future subject.

\section{Conclusion}

In this study, I estimate the consumer welfare effect caused by the BSE testing revision through an analysis of the meat demand system. The result of the analysis is that the sample average of expected CV is estimated as $214 \mathrm{yen} /$ household $\cdot$ month and the median 55 yen/household $\cdot$ month. The whole consumer welfare effect calculated based on these estimates significantly exceeds the necessary cost to continue blanket testing (0.30.4 billion yen/year). Therefore, from the perspective of cost-benefit analysis, it would be valid to continue blanket testing at present. Also, compared with the economic effects of the past BSE crisis or BSE testing, which were analyzed by Oniki [20] and McCluskey et al. [17], the effect of the testing revision seems to be rather large.

Nevertheless, the welfare loss predicted at present may be reduced by tackling consumers' cognitive lack regarding BSE risk and the risk reduction effect of blanket testing, or their distrust of the thoroughness of BSE testing. Yet I cannot analyze these reduction effects sufficiently here and leave it as a further subject.

1) According to a survey of public opinion conducted by the Ministry of Health, Labor and Welfare, about $90 \%$ of opinions were opposed to the testing revision.

2) The incomplete demand system model specifies a demand system only for a certain group of goods (e.g. meat items) as functions of prices of the group and income. Thus those demand functions don't explicitly contain prices of the other goods; in this sense, this demand system is named "incomplete." Nevertheless, under an assumption that the price of the composite of other goods is constant among all consumers, those functions can implicitly contain the composite price.

3) The Kuhn-Tucker approach and the AmemiyaTobin approach were suggested by Wales and Woodland [31]. Amemiya-Tobin approach specifies a latent demand system model without 
nonnegativity constraints and estimates it using a generalized tobit model. That is, the Amemiya-Tobin approach doesn't explain the occurrence of a corner solution in a form that is compatible with consumer theory and allows the demand to be negative in its latent model. In contrast, the Kuhn-Tucker approach has theoretical compatibility as mentioned and its parameters are estimated in values that automatically satisfy nonnegativety constraints.

4) FIES has a slight weakness that its sample size is not very large-about 9, 000 households. In contrast, the National Survey of Family Income and Expenditure, which is conducted once in five years in place of FIES, increases the sample size to about 60, 000 households.

On the other hand, the representativeness of WMS is guaranteed in the sense that it records all sales in the wholesale markets. But the rate of perishables which pass through the wholesale market tends to decline year by year. For example, the rate of fresh meat was $13.4 \%$ in 2002, so WMS does not represent all demand and supply of the whole meat market. Also, as pointed out by Yoshino [33], we should recognize that WMS is a transaction record between sellers and buyers in the wholesale market, not a demand record for the end-consumers.

POS data also possesses certain representativeness in a sense that it records all sales in the corresponding retail store. Yet, almost all consumers don't go to the same store in every shopping opportunity, so a single store's data can't capture the whole expenditure of residents living around the store.

5) Burton and Young [3], Flake and Petterson [7] and Verbeke and Ward [30] attempted similar analyses by using the same type of data in the UK, the US and Belgium, respectively.

6) Abroad, Latouche et al. [14], Dickinson and Bailey [6] and Lusk et al. [15] evaluated the safety of beef and they also simplified the question settings in a similar manner.

7) This survey was carried out as a part of "Research Concerning Economic Evaluation and Optimization of Risk Management for BSE” under the auspices of the Ministry of Agriculture, Forestry and Fisheries.

8) Concretely, I reported "in the monitoring survey period, your purchase quantity of domestic beef was $\bigcirc \bigcirc \bigcirc$ gram, American beef was 00 gram, ...," "your average purchase price of domestic beef was $\square \square \square$ yen per 100 gram, American beef was $\square$ yen, ..., " “as a reference, the national average market price of domestic beef is $\diamond \diamond \diamond$ yen per 100 gram, American beef is yen, ..." The average market price was calculated using the database of the Agri- culture and Livestock Industry Corporation (ALIC): for domestic beef, Australian beef, pork and chicken, the average from 2001 to 2005 was calculated, for American beef, the average from 2002 to 2004 .

9) There are the other kinds of single substitution method such as "Mean," "Worst" and "Hot Deck." "Mean" fills missing parts with the average of observed values, and "Worst" fills the most unfavorable value of the observations. In spite of such ease, these methods fill all missing parts with the same value, so it is feared that they significantly lose the original variation of the corresponding variable if there are many missing values. In addition, since the value substituted in "Worst" is biased, this method also makes a bias in the average of the variable regardless of its missing mechanism. Meanwhile, for each missing unit, "Hot Deck" looks for another unit which possesses similar background data and fills with the observed value of the similar unit. But it is not always easy to look for similar units and it is not necessarily clear how much should be similar.

10) Originally it would be ideal to assume joint normal distribution which makes no assumption of covariance structure of errors. In this case, however, the likelihood function doesn't become closed-form, and we have to simulate its approximate. Yet there is a technical problem that the simulation times that must be done increase in geometrical progression as the items to be analyzed increase. According to Cornick et al. [4], if we analyze more than four items, then the calculation amount exceeds the capacity of a computer and the simulation itself becomes impossible. This study suffers from this problem because it focuses on five items. This is the reason why I assumed GEV distribution.

11) The indirect utility function derived from equation (12) takes the form of a logarithmic function of food expenditure, so CV derived from it takes the form of an exponential function. Thus, a random number with an extremely large value causes an extraordinarily large $\mathrm{CV}$. The procedure demonstrated here is intended to exclude these outliers. Note that the expected $\mathrm{CV}$ obtained by this procedure has a meaning similar to each monitor's median.

12) While it is possible to deal with endogeneity by the instrumental variable method, unfortunately I couldn't collect data of appropriate instruments in the survey. On the other hand, within the framework of the Amemiya-Tobin approach, Meyerhoefer et al. [19] proposed a method to deal with endogeneity with panel data. But the Amemiya-Tobin approach sacrifices 
the compatibility with consumer theory as previously mentioned.

13) Although I cannot confirm whether it is a general tendency in the GCS model, at least, the estimation result of Phaneuf et al. [22] was in the same situation as this result.

14) Definition of own price elasticity, $e_{J J} \equiv\left(\partial x_{J} /\right.$ $\left.x_{J}\right) /\left(\partial p_{J} / p_{J}\right)$, is converted to $\partial p_{J}=p_{J}\left(\partial x_{J} / x_{J}\right) /$ $e_{J J}$. Based on this relation, equation (22) is obtained by replacing $\partial p_{J}$ with $M W T A_{J}$ and $\partial x_{J}$ with $x_{J}^{1}-x_{J}^{0}$. This derivation refers to Oniki [20].

\section{References}

[1] Aizaki, H., K. Sato, T. Kikkawa and M. Sawada. "Chapter 4: Integrated Analysis of Consumers' Knowledge/Attitude for BSE and Food Safety and Their Selection Behavior for Beef Purchase," Valuing Food Safety: Stated Preference Method Approach (M. Sawada compiled), Association of Agriculture and Forestry Statistics, 2004, pp. 88-129.

[2] Aizaki, H., M. Sawada, K. Sato and T. Kikkawa. "Consumer Preferences for Production Information Disclosed Beef and BSE-tested Imported Beef: An Application of Choice Exper iments," Agricultural Information Research, Vol. 15, No. 3, 2006, pp. 293-306.

[3] Burton, M. and T. Young. "The Impact of BSE on the Demand for Beef and Other Meats in Great Britain," Applied Economics, Vol. 28, No. 6, 1996, pp. 687-693.

[4] Cornick, J., T. L. Cox, and B. W. Gould. "Fluid Milk Purchases: A Multivariate Tobit Analysis," American Journal of Agricultural Economics, Vol. 76, No. 1, 1994, pp. 74-82.

[5] Deaton, A. S. and J. Muellbauer. Economics and Consumer Behavior, Cambridge University Press, 1980.

[6] Dickinson, D. L. and D. Bailey. "Meat Traceability: Are U. S. Consumers Willing to Pay for It?," Journal of Agricultural and Resource Economics, Vol. 27, No.2, 2002, pp. 348364.

[7] Flake, O. L. and P. M. Patterson. "Health, Food Safety and Meat Demand," contributed paper, American Agricultural Economics Association Annual Meetings, Nashville, TN, August, 1999 .

[8] Fuwa, N. "The Challenge of 'Endogeneity Problems' and Recent Methodological Advances in Microeconometric Studies in Development Economics," Journal of Rural Economics, Vol. 79, No. 4, 2008, pp. 233-247.

[9] Hanemann, W. M. “Discrete/Continuous Models of Consumer Demand," Econometrica, Vol. 52, No. 3, 1984, pp. 541-561.

[10] Heien, D. and C. R. Wessells. "Demand
Systems Estimation with Microdata: A Censored Regression Approach," Journal of Business \& Economic Statistics, Vol. 8, No. 3, 1990, pp. 365-371.

[11] Iwasaki, M. Foundations of Incomplete Data Analysis, Economist Sha Publishing, Inc., 2002.

[12] Jin, H. J. and W. W. Koo. "The Effect of the BSE Outbreak in Japan on Consumers' Preferences," European Review of Agricultural Economics, Vol. 30, No. 2, 2003, pp. 173-192.

[13] Katahira, H. A New Approach to Consumer Choice Analysis: Theory and Application of LOGMAP, University of Tokyo Press, 1991.

[14] Latouche, K., P. Rainelli, and D. Vermersch. "Food Safety Issues and the BSE Scare: Some Lessons from the French Case, "Food Policy, Vol. 23, No. 5, 1998, pp. 347-356.

[15] Lusk, J. L., J. Roosen and J. A. Fox. “Demand for Beef from Cattle Administered Growth Hormones or Fed Genetically Modified Corn: A Comparison of Consumers in France, Germany, the United Kingdom, and the United States," American Journal of Agricultural Economics, Vol. 85, No. 1, 2003, pp. 16-29.

[16] Mangen, M. J. J. and A. M. Burrell. “Decomposing Preference Shifts for Meat and Fish in the Netherlands," Journal of Agricultural Economics, Vol. 52, No. 2, 2001, pp. 16-28.

[17] McCluskey, J. J., K. M. Grimsrud, H. Ouchi and T. I. Wahl. "Bovine Spongiform Encephalopathy in Japan: Consumers' Food Safety Perceptions and Willingness to Pay for Tested Beef, " the Australian Journal of Agricultural and Resource Economics, Vol. 49, No. 2, 2005, pp. 197-209.

[18] McFadden, D. “Computing Willingness-toPay in Random Utility Models, " working paper, Depertment of Economics, University of California, Berkeley, 1995.

[19] Meyerhoefer, C. D., C. K. Ranney, and D. E. Sahn. "Consistent Estimation of Censored Demand Systems Using Panel Data," American Journal of Agricultural Economics, Vol. 87, No. 3, 2005, pp. 660-672.

[20] Oniki, S. "Valuing Food-Borne Risks Using Time-Series Data: The Case of E. Coli O157: H7 and BSE Crises," Agribusiness, Vol. 22, No. 2, 2006, pp. 219-232.

[21] Peterson, H. H. and Y. J. Chen. "The Impact of BSE on Japanese Retail Meat Demand," Agribusiness, Vol. 21, No. 3, 2005, pp. 313-327.

[22] Phaneuf, D. J., C. L. Kling, and J. A. Herriges. "Estimation and Welfare Calculations in a Generalized Corner Solution Model with an Application to Recreation Demand," The Review of Economics and Statistics, Vol. 82, No. 1, 2000, pp. 83-92. 
[23] Saghaian, S. H., L. J. Maynard, and M. R. Reed. "The Effects of E. Coli O157: H7, FMD and BSE on Japanese Retail Beef Prices: A Historical Decomposition," Agribusiness, Vol. 23, No. 1, 2007, pp. 131-147.

[24] Sawada, M. "The Effects of BSE Scare and E. coli O157: H7 Outbreak on Retail Demand for Beef and Other Meats in Japan: A Demand System Analysis Using Scanner Data," the Special Issue of the Journal of Rural Economics, 1999, pp. 278-283.

[25] Sawada, M. “An Econometric Analysis of Consumer Responses, to News Reports of BSE and E-coli O157: H7 Outbreaks: The Case of Beef and Lettuce Consumption," the Special Issue of the Journal of Rural Economics, 1998, pp. 72-74.

[26] Sawada, M. compiled, Valuing Food Safety: Stated Preference Method Approach, Association of Agriculture and Forestry Statistics, 2004

[27] Sawada, M. “A Nonparametric Demand Analysis of the Structure of Consumer Preferences," Journal of Rural Economics, Vol.63, No. 1, 1991, pp. 1-10.

[28] Food Safety Commission. “Food Safety Risk Assessment Related to Measures Against Bovine Spongiform Encephalopathy (BSE) in Japan, " 2005.

[29] Ujiie, K. "Food Consumption and Information on Food Safety: A Scanner Data Analysis of the June 2000 Milk-Poisoning Outbreak,"
Journal of Rural Economics, Vol.74, No. 3, 2002, pp. 109-122.

[30] Verbeke, W. and R. W. Ward. “A Fresh Meat Almost Ideal Demand System Incorporating Negative TV Press and Advertising Impact," Agricultural Econometrics, Vol. 25, No. 3, 2001, pp. 359-374.

[31] Wales, T. J. and A. D. Woodland. "Estimation of Consumer Demand Systems with Binding Non-Negativity Constraints," Journal of Econometrics, Vol.21, No.3, 1983, pp. 263285.

[32] Wooldridge, J. M. Econometric Analysis of Cross Section and Panel Data, the MIT Press, 2001.

[33] Yamane, S. “Estimation of Consumer's Welfare Change by the Revision of Age Criterion for BSE Testing: Hypothetical Revealed Preference Method Using Monitoring Survey Data, " Nogyo Keizai Kenkyu (Journal of Rural Economics), Vol. 80, No. 1, 2008, pp. 1-16.

[34] Yoshino, A. “A Method to Measure the Index of Marketing Brand Power of Fruits and Vegetables," Journal of Rural Economics, Vol. 69, No. 3, 1997, pp. 152-165.

[35] Yoshino, A., Y. Nakajima, S. Minamiguchi, F. Yamane, and H. Takeshita. "Risk Communications on BSE Issue with Consumers," The Special Issue of the Journal of Rural Economics, 2006, pp. 166-173.

(Received January 26, 2010 ; accepted February 4, 2010) 